\title{
Somatoform and conversion disorders as psychological defences
}

\author{
Elena Andreea Mut ${ }^{\mathrm{a}}$, Cristina Pălădoiu ${ }^{\mathrm{a} *}$, Monica Stănescu ${ }^{\mathrm{a}}$ \\ ${ }^{a}$ Faculty of Psychology and Educational Sciences, 90 Panduri Str., 050663, Bucharest, Romania
}

\begin{abstract}
Conversion disorder is the clinical situation in which one or more symptoms can present deficits that affect motor or sensory function and suggest a neurological or organic condition. Psychological factors are decisive, and they usually include a major anxiety generated by intrapsychic conflicts, which are converted by unconscious defense mechanism into symptoms. The symptoms are not intentionally provoked or simulated nor are explained by organic suffering or substance consumption. They affect the quality of life of the person who presents significant deficits such as motor, sensory, convulsive or mixed. It may also occur a lack of coordination, ataxia, paralysis, tremor, aphonia, difficulties at swallowing, loss of sensitivity, anesthesia that does not follow anatomical nervous trajectories, blindness or mental deafness. Consciousness is not altered, but a condition of "la belle indifference" appears which is rather associated with histrionic personality disorders and what the patients imagine about their own illness or suffering. This condition is unstable and changing. The primary gain is the expression of an unconscious psychological conflict through a somatic symptom by reducing anxiety and keeping conflict out of consciousness. The secondary gain is external and includes attention and care from caregivers or others.
\end{abstract}

Keywords: apatho-abulic dimension; behavioral dimension; depressive dimension; alcoholismschizophrenia; family medical history; family support; social support

\section{Dissociative pathology and the concept of hysteria}

In psychotic disorders, patients lose their sense of reality and they do not assume their illness or ask for help. Moreover, hallucinations appear, delusional ideas and a certain lack of insight.

In neurotic pathology, the patient knows something is wrong with himself, knows that he can no longer function as he used to and asks for professional help.

The area of personality disorders does not necessarily belong to psychiatry. We meet it rather outside of psychiatry, most likely in psychotherapy clinics, but it depends on the type of personality disorder, because there are patients who ask for help and patients that do not.

In the old days there was the concept of hysteria, a concept that everyone had heard of, but which now scares, as it was described by Freud. Around the 1900s there was a lot of talk about this aspect. Now the word no longer exists in psychiatry because it has a negative connotation and specialists can no longer afford to describe a patient as hysterical. In case a specialist does so it is considered an ethical mistake or an assertion in an informal environment. Hysteria has remained a laic word, but it is not known exactly what it means. Popularly, hysteria would be synonymous with choleric temperament.

In the field of psychiatry, Freud's concept is linked to Charcot's hysteria. It refers to those crises in which someone enters and remains in a state of conceit. For example, in a hysterical arch, a woman who tenses her muscle so hard that she looks like she is

\footnotetext{
* Corresponding author. Tel.: +40-725240125

E-mail address: cristinapadaoiu@gmail.com
} 
in a bridge position supported only by her heels and head. This was first described as Charcot's hysteria in the 1900s as a hyperextension. These crises were more specific to women. Psychiatry changes over the years, and such things are rarely encountered. The word hysteria was "divided" into three zones: the psychotic zone, the neurotic zone and the personality disorder zone.

\section{Hysteria in personality disorders}

In the area of personality disorders, it is easier to understand the concept as the histrionic personality includes the criteria of DSM psychologically described by seduction, theatricality, demonstration, women who use the body or their own sexuality to attract men, to conquer. But it is not found as hysterical personality, but histrionic personality. It is a B cluster personality disorder that includes borderline disorder, narcissistic disorder and antisocial disorder (histrionic disorder being in a second place in terms of a relative scaling of emotionality).

\section{Histrionic personality disorder versus borderline personality disorder}

Unlike borderline, patients with histrionic personality do not engage too many storms of affections. Borderline personality is the one masterfully loaded with emotions, feelings and feelings; comes towards you, plays emotions in dynamics with another, in relation to you. The one who is histrionic rather seeks to mimic all these things.

The borderline patient can threaten suicide and has parasuicidal behaviors with selfmutilation, dangerous driving, threats to kill, displays that in his intrinsic dynamics are extremely authentic. And they can even risk doing these things. Those who are histrions do not touch themselves in a self-aggressive manner, not even by mistake or demonstration. Histrions play a show and threaten suicide, but they do not have the courage to act.

The term hysteroid - psychiatrists have less to do with this concept, but psychologists find it in the Szondian terminology (hysterical personality imprinted by hysteria). In this situation, hysteria is deeply fixed in the personality structure and is associated with certain tendencies of emotional coldness. It is like patients are photographing the behavior of another person with a kind of "as if". From such a perspective it is like we are talking about a false self. The more the patient is fixed in these attitudes, the more he is called a hysteroid (old school psychological terminology).

In the old days, psychosis was divided into two main groups - hysterical psychosis and schizophrenic psychosis. For hysterical psychosis the word dissociation was used (i.e., the personality of the patient was dissociated /split) and for schizophrenic psychosis the term split. They are exceptionally fine terms and should be used correctly in clinical psychology and particularly in the evaluation processes.

In dissociation, it is as if there is an artificially "mounted" transverse wall, but with a protective role from top to bottom. This mechanism is like a massive wall, there may be several personalities who have several fragments or "pieces" of the personality of the individual concerned, but he does not necessarily know what is beyond the tangible, located either here or on the other side of the barricade. The pieces of Ego sometimes communicate with each other, so the purpose of antipsychotic drugs is to make this wall more fragile, in the idea of making it more permeable, that the parts of Ego begin to communicate with each other again.

In split, in schizophrenia or schizophrenic psychosis, also as a metaphorical representation, we can guide ourselves after the Tree Test - most schizophrenics will draw a trunk and then very quickly, from that trunk, will start two branches. In the split there is a common trunk area. "The concrete wall" is not completely from top to bottom, but starts from an initial, after which its later breaks. For schizophrenia and schizophrenic psychosis there is even frequently used metaphor of breaking the Ego unity. 
Schizophrenic patients are significantly emptier of affections, more or less metaphorically, with an empty look (in The Faces Test). This is a pathognomonic sign of emptiness and emotional emptiness within their being. Hysterical psychosis has a more colorful range of affects and more related to sexuality.

Hysterical psychosis (more common in women) shows significantly better remission. Some of these patients go through severe episodes of regression (use adult diapers, eat in bed, feed on the spoon; if they are younger women, they need mothers to sit next to them or husbands and if possible, they may be treated like babies). It is a massive regression to a primitive behavior. But these episodes pass and the following significant periods of improvement are much greater than in schizophrenic psychosis (longer duration and better quality).

There is a good response to Haloperidol: It would be believed that Haloperidol is now only used in the ER, in psychiatric emergencies with violent behavioral syndrome or in small doses in pathologies that require clarification of the field of consciousness and that now, modern, atypical antipsychotics are preferred. But this subtype of hysterical psychosis- increasingly rare in modern psychiatry - responds well only to Haloperidol.

\section{Trance and possession disorder}

In modern psychiatry this type of hysterical psychosis is no longer found in DSM$\mathrm{V}$, but there is a clinical entity named Trance and possession disorder. Trance and possession disorder are a stand-alone mental disorder with a separate code and specifically explained in DSM. Schizophrenia has not been assimilated, but it is also not included in the neurotic disorders' category. In short, the patient considers himself possessed. Speech at the level of thought predominates in delusional ideas that are of trance and possession ("The devil entered me, I have snakes that walk through my body, I am possessed, I feel that I transform"), which can be accompanied partially by perception disorders, mainly tactile, somatic or visceral and in congruence with the main delusional themes (sometimes amplified or potentiated subcultural).

The trance and possession disorder is rarely seen in intellectuals or highly educated people, you (the classic examples would include: mercury circulating under the skin, spells, snakes tucked into the body).

Example 1: M: hysterical psychosis versus schizophrenia

The patient has a pervasive psychotic speech centered on three witches (who charm her, brought her men or took the men from her house). Although she is 38 years old, she is an extremely regressed patient. She has a spectacular speech that includes witches, curses, tin, how she felt haunted or possessed by all kinds of entities. In the image of the three witches it is noticed the mechanism of projection on her other three sisters All four of them were very united during childhood and adolescence, but life led them on different paths, and now they were arguing over the wealth represented by the parental home, as the only line of protection and security especially for M., who had a psychiatric disorder that affected her reality testing. $M$ also displayed another side of herself- in which she was going to the sewing machine and things were pretty good. Her speech was over sexualized. As an example, she saw a little angel with a very large penis, who was circling her every day. In everyday life, if she was talked to about men, she said repulsively: "Oh, no, men must get out of here, away from me, I'm afraid of them and I don't like them!". All her behavior was of a little girl regressed at kindergarten: "I only stay with the girls, I want my sister...". All this suggests feelings of rejection from the hysterical strand ("sexuality, penis, masculinity to leave and not exist in my life").

The case of $\mathrm{M}$ is around the concept of hysterical psychosis. Currently, hysterical psychosis no longer exists as such, it has been abolished in the last DSMs and assimilated to the large category of schizophrenia, although as we well know, theoretically as Bleuer asserts, there are forms of schizophrenia that may rather resemble another mental illness, than forms of schizophrenia that resemble each other.

Example 2: Nurse, Trance and possession disorder versus TPSA versus simulation 
A nurse cuts her husband's face. This is how, what would seem like a story written in a psychiatric hospital, begins. At some point, during the period of time of two years when she was admitted based on art. CPP 110 , the patient perfectly mimicked a trance and possession disorder. She was convinced that she was pregnant with the devil that horns were growing from her head. Being taken to the electroencephalogram, she ripped the wires off her head, jumped up and beat those around her and said that the EEG wires were the horns that grow after reuniting with the Unclean. He looked at her fingernails and said, "look, my claws have grown, these nails are my claws and I'm going to turn into the devil, my belly swells, I'm pregnant." At the same time, she also hit the clinical psychologist and snapped the pictures of the Szondi Test.

The hysteria reflected in the neurotic area was divided into several clinical diagnostics entities: somatization disorders, conversion disorders, dissociative disorders.

Somatization disorder is very often found in the practice of somatic physicians, i.e., in hospitals of somatic diseases. In principle, somatization disorder rarely reaches a psychiatrist or psychologist. Most of the time it starts with a quantitative disturbance of perception, with some excess bodily sensations.

\section{Quantitative perception disorders - Dupré cenesthopathy}

At any time we strive to do things, we have all kinds of experiences inside our body (you may be annoyed by one of your new shoes, you may have not eaten and feel like you have a hole inside the stomach, abdominal cramps, burns in the pelvic area, etc.)., but the next moment you no longer pay attention to them. That is, the attention filter works well enough to drive them away and consider them to be sensation. This way, attention helps focus on what you must do now, to pay attention to the main activity required at that time.

Cenesthopathy is a combined disorder: hyperesthesia (decrease in sensory threshold) accompanied by hypersensitivity. Thus, with a low sensory threshold, the person perceives sensory signals of much lower intensity that normally someone else would not perceive. The cerebral cortex is "bombarded" with a lot of information. The attention filter does not work anymore to stop them, and then these people may end up living an intense state of anxiety ("something bad is happening to me and my body").

The Dupré cenesthopathies appear predominantly at the abdominal level. Most of them are migratory. This means that they are quite easy detected by a physician because a medical pain is usually at a fixed point or is in a certain region. Cenesthopathies have a variable, parasitic and embarrassing character. That is, the patient wants to "escape" and fight them, to set them aside, but fails because of their recurrence and persistence. These sensations still come and are unaccompanied by visible macroscopic anatomical disturbances (i.e., nothing is detected at the somatic level following the analyses). Then we say that they remain at the functional level, do not pass into the organic one. It is not possible to know with present medical means and knowledge if there are however some small "disruptions" at the level of their respective areas. But we are talking about disturbances that are not seen anatomically, but can be seen, for example, if we study aspects at the pathophysiology level, such as the permeability of calcium, sodium, potassium, chlorine, magnesium, prostaglandins level or interleukins involvement in pain medication. This means that something specific at the physiopathology level may have caused a disturbance, but it has not yet come to cause anatomical changes. Starting with the Cenesthopathies Dupré, Somatization Disorder is built. That is, when these cenesthopathies are too many and do not remit, they get structured and begin to build the somatization disorder, which can be complete or incomplete (depending on how many criteria it meets). Somatization disorder occurs early, around the age of 30 and it is more common in women and patients with low social backgrounds and less access to culture and education.

Somatic physicians would say that these cenesthopathic patients should be left alone, that they should not be given too much attention, that there are no ways to 
convince them that they are not sick. If these patients are ultimately persuaded to come to psychotherapy, they should never be told that their pain is not real. Doctors also make this mistake and say for example that "he's a fancied patient", that "it seems", "look you have nothing, the tests are normal". The correct attitude would be to tell the patient, for example: "I understand that your pain is extremely vivid, that these localizations move from one place to another and from one day to the next, I understand your suffering, especially since it is exceedingly difficult to carry it on. However, it is not objective by using the usual investigative modalities and therefore we consider it as being part of a different issue, we believe that the psychiatric medication will help you with your suffering". In any case, pain should not be denied, because it is there and suffering is present, even if it is not objective.

\section{Somatoform disorder and hidden depression}

Somatoform disorder is more common in people from certain subcultural backgrounds (not necessarily with less education, but people "unprocessed souls"). From a psychiatric perspective, somatization disorder has certain criteria. From the perspective of psychodynamic psychiatry, one always tries to see what is behind it, one step at the time. The unconscious is considered in fact, a masked depression and the patient is not elaborate enough to be able to live experience own depression. This way the patient experiences somatization. It is not always a direct relationship between the fact that someone has only attended four classes and does not own an elaborate soul. There are patients who only attended four classes, but they have a brilliant elaboration of their inner world, as there are patients who finished colleges and postgraduate studies- but have no capacity for metaphor and symbolization.

This somatization disorder is remarkably close related to the concept of hidden depression or masked depression. In this case, the patient cannot experience his depression with his soul, but lives it with his whole body. The patient does not even know that he's sad or upset, he is not crying or whining, he is not in touch with his suffering at all. Instead, depression takes somatic forms (muscle pain, bone pain, back pain, different regions of the body, all with a migratory character). It is the Freudian mechanism that makes the leap from mental to somatic, because to live depression certain capacity for symbolization is needed, which develops inside the soul. Depression is experienced in a world where the patient expresses it, weeps, experiences a mourning labor and all sorts of things happen in his own inner space. But in the somatization disorder it is as if the whole soul is short-circuited. That is, the symbolic space where conflicts should be drawn up and talked about or to put into words is absent.

The absence of this metaphorical space where to mourn is a difficult obstacle to overcome for psychotherapists. No matter what therapy technique you master, the goal is to put things together, that is to get over the somatization and discover what conflicts, what troubles and torments that patient experience. Then you may teach the patient to draw them down and tie them up, but find yourself in an unfortunate situation of having whole sessions, where you know how to have interviews and ask you about things that seem relevant (about the husband, job, children, about all areas of mental life), but the patient, although tells you that he has been in trouble and you encourage him to develop the subject, along with the adjacent emotions (both those of the past and those present) and he actually replies that he came to talk about how it hurts, about his somatic sufferings, about how he does not understand the connection between the questions you ask him and what he describes and lastly that he paid for psychotherapy because he understood that it was a space where he could "spill out" the suffering. Over the course of several sessions, things come to light, but the challenge is to bind them together, to elaborate them and to remove them from the body and to bring them into a space of the soul, where one can work with feelings, emotions, feelings, passions, unhappiness, frustrations. It's hard because such an individual doesn't know, he's never been taught how to do it. This kind of people were not developed from early childhood until the age at when they came to develop something other than a somatization disorder (often, this is taken up by translating 
role models from someone important in the family). It takes a certain ability to experience depression, it takes a sufficiently solid and elaborate inner structure to be able to carry mourning and suffering. In the somatization disorder it is met such primitive structures, who instead of living with the mind or soul, live directly with the body (Trifu, 2015).

Another psychological mechanism is symbolic identification with a member of the family who once experienced the same type of suffering. For example, a 30-year-old woman- who still has an 80-year-old grandmother alive - the grandmother has had a stroke and is experiencing all the related somatic suffering - and the young woman is in fusion, in symbiosis with her grandmother; so she walks around all the doctors because she somehow took over from the grandmother's symptoms - without there being an organic substrate - which leads her to a "doctor shopping" behavior (Trifu, 2019).

The differences between somatization and hypochondriac disorder can be structured as: somatization is long experienced in the body and the whole description is related to bodily symptoms. Hypochondriac disorder develops in the thought, in the idea. The less the patient lives with the body, but the more with the idea, his belief is that he has an incurable disease.

\section{How subjects with somatization disorder should be approached}

These subjects are passed from one specialist to another, because no one has the time or necessary patience for their emotional needs and, above all, their relationship needs. Usually, patients with somatization disorder exhaust all medical specialties until they reach psychiatry.

Finally, it is good if they end up in the psychiatric ward, because hidden depression also heals with antidepressants (both from the point of view of modern psychiatry and from the point of view of psychodynamic psychiatry, abysmal psychology, symbolic approach). Pharmacologically, depression receptors are all over the body. Thus, a treatment with antidepressants also reaches the serotonin receptors, which are also in the digestive tract, repair what they have to repair and thus the pain disappears. If these people get to psychiatry, they start to feel better relatively quickly. If they get to the psychologist, it is possible that for whole sessions the patient is concerned to describe the somatic accusations and not to let the therapist address the conflicts (hard barrier to cross!). Mainly, sedative antidepressants are used (tricyclics type Doxepin or Amitriptyline, which work very well on pain or antidepressant and modern dual type Mirtazapine, Duloxetine or Milnacipran, used as step augmentations in the pathologist of somatic pain). Adjacently, the anguish must be calmed.

According to Merck Sharpe \& Dome Manual of Diagnosis and Therapy, these patients should be cared for by the family doctor. The latter should set time limit for the appointment, i.e. not to let the patient overwhelm him, because he is able to talk for hours about his somatic pains and sufferings. It is recommended that the patient be given short and frequent appointments (approximately 30 minutes every two other weeks).

\section{Conversion disorder}

Starting from the example of a 40-year-old Roma patient who borrowed about 400 million lei somewhere around 2002 (then being much more valuable than at present). The patient had given this money to bulibasha (a person highly sworn in in his culture and ethnicity). In short, she had lost the money and could not return it as she lost all of it. The situation escalated, leading to a family brawl where the patient tried to beat her. According to their cultural norms, the relatives would never allow themselves to fight a hierarchically invested personality. The moment the women tried to hit her, she was left with her hand in the air, paralyzed. Also, she developed paralysis both in the hand and leg on the same side, as well as her mouth. If someone saw her in those moments, she looked like a young woman in her 40s, with the symptoms of a genuine stroke. Communication was reduced to dysarthria and, finally, to aphonia. 
Due to the inability to speak and the inability to use her hand and leg (genuine functional paralysis), the family went to multiple neurological checks and investigations; once in psychiatry, all the relatives visited her, being scared. She did several neuroimaging analyses- the results were coming out within the broad limits of normality, thus determining that there were no organic causes. Psychiatric admission lasted two weeks.

Unlike somatization disorder, where symptoms last long (up to years) and are hard to recover, in conversion disorder there is a chance to have a relapse rate of about $25 \%$ in the following year and a half, if a conflict situation is repeated. In this case, the symptomatology recovered altogether in about a month and a half, with family involvement and life situation management. (McWilliams, 1994; Tereanu, 2011)

The literature states that similar episodes can still occur during their lifetime under the same conditions of direct connection to an event. Although it seems a „milder” disorder in terms of the risk of evolution, the symptomatology is more spectacular.

Description of the conversion disorder (jumping from psychological to somatic), according to the literature, involves the following features: sudden debut; close and direct connection with a psychological trauma (occurs immediately or at a short interval from a traumatic situation/event: from 30 minutes to a maximum of 3 hours); the symptom has a gest with symbolic significance (customized in the case described above, the paralyzed arm represents the aggressiveness that is not allowed to the person concerned to externalize it and then it turns to itself, the symptom "stabilizes" in the hand and foot and paralyzes it); according to the literature, in all cases of conversion, if you have the patience to analyze them, you will find the symbolic significance of the symptom, which differs greatly depending on how the specialist who manages the case interprets it (in the example given, the lady mimics the stroke very well, by the presence of hemiplegia and aphonia) (Putnam, 1986).

Conversion disorder criteria are at least: patients have deficits affecting motor or sensory function and suggest a neurological or organic condition; psychological factors are associated; the occurrence or exacerbation of symptomatology is preceded by conflicts or psycho -traumatic factors; symptoms are not intentionally caused or simulated; symptoms are not explained by organic suffering or substance use; symptoms look more the way the patients imagine their disease and suffering than like what is really happening and can be changeable; symptoms cause suffering and affect the life of the subject, through deficits, be they motor, sensory, mixed, convulsions or hysterical crisis;

The conversive symptoms can be motor: lack of coordination, ataxia (need for a broad and supportive base, does not stand), paralysis (which may be mono-, hemi- or tetraplegia); muscle weakness; tremor; aphonia; difficult swallowing (which may also be for solids and liquids), subjective sensation of pharyngeal node or bladder; sensorial: loss of sensitivity (anesthesia in the hand, in the sock, which does not respect the anatomical pathways), paresthesia, double/ triple vision, blindness, deafness; seizures: seizures $=$ conversive seizures; popularly named hysterical seizures or functional seizures and mimic very well epileptic seizures; spasmophilia seizures: crises where people remain with their hands in a specific attitude, called the mother's hand and tense legs, manifesting themselves as extremely painful moles, which are placed in both the upper and lower limbs, the body remains fixed in a certain painful position; spasmophilia means decrease dismay of calcium $(10 \mathrm{ml} / \mathrm{dl} \rightarrow$ below $7 \mathrm{ml} / \mathrm{dl}$ ); most often, such patients reach emergencies; in hospitals this diagnosis is made, although the patient has symptoms of functional seizures, and thus people can worsen their condition (for example, this diagnosis can be like "a sand thread" inside where the pearl is built).

\section{Types of gains directly related to conversive pathology}

Primary gain is a psychodynamic concept. It refers to the psychological process through which the pathology takes place unconsciously, not a simulated one. It is as if the unconscious chooses, and choice is what is most at its fingertips, even if it is made of two evils. But it causes the lowest degree of accessible suffering. (An example of a 
choice that causes severe suffering would be auditory hallucinations of self-harm or depression, polymorphic delusional ideas, violent dysbehavioral syndrome). Then, the subject makes "a rapid unconscious calculation" between all these evils and chooses the least possible evil. The mechanism is called primary gain (Trifu, 2020). According to the definition, the primary gain is the expression of an unconscious psychological conflict through a symptom, the aim being to reduce anxiety and keep the conflict out of the field of consciousness.

Secondary gains are easy to understand. They are related to reality (the Roma lady arrived at the hospital because she lost a lot of money, her relatives that came to help financially and resolve the conflict, later discovered that she wanted to see if she could benefit from a medical retirement). It is those gains that someone can get out of sick status. According to the definition: the secondary benefit is attention and care.

\section{Discussion}

The first and major step is to exclude real somatic pathology because, usually the symptoms are multiple and include gastrointestinal, cardiopulmonary, genitourinary, musculoskeletal and neurologic complaints (Popa, 2019).

Strategies for using psychotherapy include cognitive behavioral therapy and expressive-supportive therapy. A detailed history, in which the physical symptoms are revised on each occasion and in minute detail, it often helps. This task assures patients that their physical symptoms are not rejected or overlooked. A rational cognitive framework for understanding their symptoms usually helps patients. Also, family therapy helps the patient and is almost always necessary. The families accept and know that the neurological deficits are caused by a psychic disability. Always the pharmacology psychiatric treatment must be associated.

\section{References}

1. Adler, A. (2010). Understanding Human Nature. Eastford: Martino Fine Books; Tra edition.

2. Bion, W. (1904). Second Thoughts: Selected Papers on Psychoanalysis. New York: Karnac Books.

3. Bowlby, J. (1976). Separation: Anxiety and Anger (Basic Books Classics) Volume 2 (Attachment and Loss Vol 2). 1st Edition. New York: Basic Books.

4. Braun, G. B. (2018). Psychotherapy of the Survivor of Incest with a Dissociative Disorder Psychiatric Clinic of North America Volume 12, Issue 2, June 1989, Pages 307-324.

5. Bliss, E. L., Jeppsen, E. A. (1985). Prevalence of multiple personality among inpatients and outpatients. American Journal of Psychiatry 142(2):250.

6. Cassidy, J., Shaver, P. (2016). Handbook of Attachment, Third Edition: Theory, Research, and Clinical Applications. 3rd Edition. New York: The Guilford Press.

7. Dunbar, H. F. (1947). Mind and Body: Psychosomatic Medicine. New York: Random House.

8. Durkheim, E., Simson, G. (1997). Suicide: a study in sociology. Forence: Free Press; Reissue edition.

9. Freud, S. (2014). Sigmund Freud 7 Book Premium Collection: General Introduction to Psychoanalysis; Totem and Taboo: Interpretation Of Dreams; Dream Psychology; and many more (Timeless Wisdom Collection 626). Kindle Edition. Business and Leadership Publishing.

10. Gavin, A., Singh, M., Bond, M. (1993). The Defense Style Questionnaire. Arlington: America Psychiatric Association.

11. Gabbard, G. (2014). Treatise on psychodynamic psychiatry. Bucharest: Editura Trei.

12. Holmes, T., Rahe, R. (1967). The Social Readjustment Rating Scale. Journal of Psychosomatic Research, 213-221.

13. Kernberg, O. (1995). Borderline Conditions and Pathological Narcissism (The Master Work Series). Lanham: Jason Aronson, Inc.

14. Klein, M. (2011). Love, Guilt and Reparation Kindle Edition. New York: Vintage.

15. Kohut, H. (2009). The Analysis of the Self: A Systematic Approach to the Psychoanalytic Treatment of Narcissistic Personality Disorders. Chicago: The University of Chicago Press. 
16. Lefter, S. (2020) A study on the structure of Self in personality disorders and attachment disorders: narcissistic personality disorder and histrionic personality disorder. Journal of Educational Sciences and Psychology, 10(1), 149-157.

17. McDougall, J. (1989). Theaters of The Body: A Psychoanalytic Approach to Psychosomatic Illness. New York: W.W. Norton \& Company.

18. McWilliams, N. (1994). Psychoanalytic diagnosis. The Guildford Press, New York.

19. Minca, D.G., Furtunescu, F.L., Calinoiu, G., Domnariu, C.D., Costea, R.V. (2013). Profile of persons involved in traffic accidents in Romania. Romanian journal of legal medicine 21(2), 155-160.

20. Popa, C. C., Badiu, D. C., Andronache, L. F., Costea, R. V., Neagu, S. I., Stoian, A. P., Socea, B., Ionescu, D. (2019). Differential Diagnosis in Esophageal Cancer Review on literature. Rev. Chim. 70(1), 331-335.

21. Putnam, F. W., Guroff, J. J., Silberman, E. K., Barban, L. (1986). The clinical phenomenology of multiple personality disorder: Review of 100 recent cases. The Journal of Clinical Psychiatry 47(6):285-93

22. Ruesch, J. (1948). The Infantile Personality - The Core Problem of Psychosomatic Medicine. Psychosomatic Medicine, 134-144.

23. Sivik, T., Schoenfeld, R. (2006). Psychosomatology as a theoretical paradigm of modern psychosomatic medicine. International Congress Series, 23-28.

24. Spiegel, D. (1984). Multiple personality as a post-traumatic stress disorder. Psychiatric Clinics of North America, 7(1), 101-110.

25. Stan, E., Safta, C. G. (2020). Evaluation and its motivational impact. Case study - future primary school teachers. Journal of Educational Sciences \& Psychology, 10(2), 03-10.

26. Tereanu, C., Minca, D. G., Costea, R., Janta, D., Grego, S., Ravera, L., Pezzano, D.,Vigano, P. (2011). ExpIR-RO: A Collaborative International Project for Experimenting Voluntary Incident Reporting in the Public Healthcare Sector in Romania. Iranian journal of public health 40(1), 22-31.

27. Trifu, S., Marica, S., Brăileanu. D., Carp, E. G., Gutt, A.M. (2015). Teaching Psychiatric Concepts of Neurosis, Psychosis and Borderline Pathology. Conceptual Boundaries. Procedia Social and Behavioral Sciences, 203, 125-129.

28. Trifu, S., Vladuti, A., Popescu, A. (2019). Neuroendocrine Aspects of Pregnancy an Postpartum Depression. Acta Endocrinologica-Bucharest, 15(3), 410-415.

29. Trifu, S., Tudor, A., Rădulescu, I. (2020). Aggressive behavior in psychiatric patients in relation to hormonal imbalance (Review). Experimental and Therapeutic Medicine, 20, 3483-3487.

30. Trifu, S., Vladuti, A., Trifu, A.I. (2020). Genetic aspects in schizophrenia. Receptoral theories. Metabolic theories. Romanian journal of morphology and embryology, 61(1), 25-32, 2020. 